\title{
Monitoring Area Perkebunan Kopi dan Kubis Serta Pohon Pelindung (Pinus) dengan Menggunakan Teknologi WSN (Wirelesss Sensor Network ) dan Computer Vision
}

\author{
Muhammad Benny Chaniago \\ Program Studi Sistem Informasi \\ Universitas Widyatama \\ Bandung \\ benny.chaniago@,widyatama.ac.id
}

\author{
Ari Purno Wahyu Wibowo \\ Program Studi Sistem Informasi \\ Universitas Widyatama \\ Bandung \\ ari.purno@,widyatama.ac.id
}

\begin{abstract}
Abstrak-Perkebunan merupakan sebuah area atau bidang kegiatan yang dilakukan oleh petani untuk bercocok tanam. Area perkebunan membutuhkan pengawasan dalam prosesnya dan aktivitas ini membutuhkan effort yang sangat besar oleh setiap petani. Dengan berkembangnya teknologi informasi saat ini, ada beberapa teknologi yang dapat diadopsi oleh petani dalam aktivitas pengawasan perkebunannya dengan menggunakan teknologi WSN dan computer vision. Kedua teknologi ini dapat menjadikan kegiatan petani lebih efektif dan efisien karena sistem pengawasan dapat dilakukan dari jarak jauh untuk memonitor kondisi perkebunannya, baik dalam kondisi normal ataupun dalam kondisi tanaman membutuhkan treatment dikarenakan kekurangan air atau terkena hama penyakit. Pada penelitian ini penerapan teknologi tersebut dapat membantu petani dalam mengelola perkebunannya menjadi lebih efektif dan efisien sehingga dapat melakukan panen pada perkebunan dengan produksi lebih banyak lagi dan dengan kualitas yang semakin baik.
\end{abstract}

Keyword: WSN, Computer Vision, Perkebunan

Article history:

Received: 20 Feb 2019 Received in revised form: 17 March 2019 Accepted: 23 April 2019 Available online: April 2019

\section{PENDAHULUAN}

Perkebunan merupakan sebuah area atau bidang kegiatan yang dilakukan oleh petani untuk bercocok tanam. Indonesia merupakan sebuah negara agraris yang masih mengandalkan hasil dari perkebunan sebagai penyumbang devisa terbesar setelah migas dan sektor perikanan. Beberapa perkebunan produktif di Indonesia telah dilakukan sejak zaman kolonial belanda, dimana perkebunan kopi dibuka di area yang strategis dengan dilengkapi oleh jalan raya dan sumber air. Jenis perkebunan produktif tersebut adalah kina, teh dan cokelat sedangkan perkebunan baru adalah sawit yang banyak dibuka di daerah Sumatera dan Kalimantan.

Area perkebunan saat ini sudah sangat banyak, ada yang dikelola oleh swasta dan pemerintah. Dengan bantuan dari pihak tersebut maka sistem pengawasan dan monitoring dapat dengan mudah dilakukan karena didukung oleh dana dan peralatan yang modern, sedangkan masalah yang dihadapi saat ini adalah bagaimana membuat sebuah sistem monotoring perkebunan tradisional dan pada area lahan yang terbatas. Lokasi perkebunan tradisional banyak yang menanam tanaman yang memiliki nilai jual yang tinggi dan tidak kalah dengan perkebunan yang dibuka oleh pihak swasta atau pemerintah. Perkebunan tradisional biasa dibuka dekat hutan lindung dan masih menyisakan pohon nauangan, di daerah Jawa Barat khususnya daerah perkebunan dibuka pada arae dekat dengan perbukitan dan berundak-undak, sebagai contoh daerah sekitaran kaki Gunung Manglayang, Gunung Puntang dan Sumedang. Hasil perkebunan kopi 
tersebut dirasa belum optimal karena luasnya area sehingga diperlukan waktu yang lama dalam proses pengawasan dan sistem pengaturan unsur lainnya seperti pupuk dan pengawasan terhadap hama penyakit.

Pada perkembangan teknologi saat ini, beberapa konsep pertanian modern banyak diimplementasikan dengan biaya dan teknologi yang lumayan mahal dan hanya terjangkau oleh perkebunan swasta dan pemerintah.

Penerapan konsep pertanian modern tersebut mampu meningkatkan hasil panen dan memotoring hasil perkebunan tersebut. Paper penelitian ini akan menjelaskan penerapan sebuah teknologi pertanian modern dengan menggunakan teknologi komputerisasi. Pada area perkebunan akan dipasang beberapa sensor dan kamera pengawas yang akan mengirimkan data secara paralel dan dapat digunakan secara mobile. Teknologi computer vision memungkinkan dipergunakan untuk mendeteksi hama dan penyakit yang menyerang pada perkebunan tersebut sehingga sistem monotoring dapat terbantu dan menghemat waktu. Agar sistem terbut bisa berjalan maka diperlukan sebuah sistem yang terintegrasi dan terkoneksi dengan sebuah server. Pada server tersebut tersimpan database jenis tanaman perkebunan dan penyekit yang menyerang serta solusi penanggulangannya. Metode computer vision yang dipasang pada kemera langsung digunakan untuk melihat keadaan perkebunan secara langsung dan melihat kondisi tanaman serta jenis vegitasi yang menyerang tanaman tersebut. Area yang luas dan jauh dengan sumber arus listrik tidak memungkinkan digunakan, maka sistem sensor akan mengambil daya dari sebuah solarcell yang dipasang pada sensor di area perkebunan. Sistem memiliki keunggulan yaitu kemudahan dalam penempatan dan penggunaan arus listrik yang rendah.

\section{LANDASAN TEORI}

Tipe identifikasi menggunakan teknik remote sensing pada area perkebunan menggunakan gelombang spectometer yang secara khusus bisa digunakan untuk mengidentifikasi tanaman. Pada beberapa aplikasi bisa dilihat dengan menggunakan pengaturan gelombang sensor yang diatur pada spectral library [1].

Identifikasi tanaman yang sehat dan tidak bisa dilihat akan diklasifikasikan dengan menggunakan metode remote sensing, yaitu dengan pengambilan data yang bisa dilakukan secara digital, dengan pendekatan sistem pengawasan. Sistem tersebut bisa digunakan untuk mendistribusikan data dan menyajikan data secara geografis yaitu berdasarkan data lahan. Aplikasi bisa menampilkan data secara geografis mengenai data kesuburan dan kelembaban tanah dengan menggunakan teknologi kamera Landsat [2].

Teknologi remote sensing mampu digunakan untuk mengoleksi data secara random yang diterapkan pada sektor pertanian. Pemasangan dan penggunaannya tidak begitu mahal. Beberapa sistem sudah dikombinasikan dengan alat drone yang digunakan untuk mengambil rangkaian citra udara sehingga mengurangi waktu monitoring dan pengawasan. Sistem pengambilan data secara realtime dan lebih presisi merupakan keunggulan tersendiri dari remote sensing dengan estimasi data yang diambil berupa data biomasa, jenis pohon, hasil panen dan penggunaan bahan organik lainnya [3].

Penggunaan teknologi thermal imaging memungkinkan adanya transformasi atau perubahan energi yang diambil dari citra satelit. Informasi dari perubahan tersebut akan diimplementasikan dengan adanya perubahan pixel yang diambil dari sumber yang berbeda data yang biasa disebut dengan data fusion [4]. 


\section{METODE PENELITIAN}

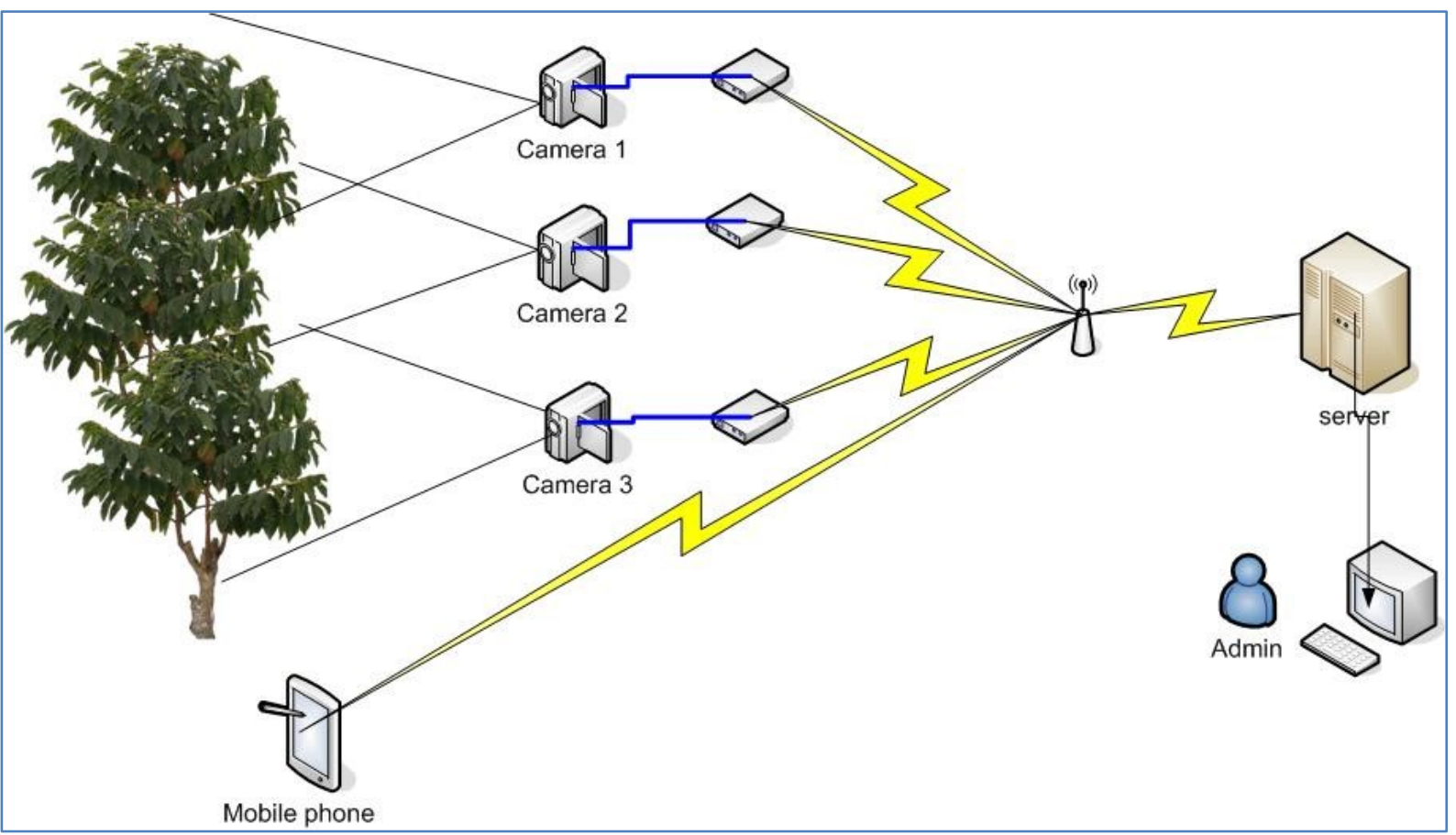

\section{Gambar 1.1 Metode Perancangan Monitoring Area Dan Tanaman Perkebunan}

\section{Keterangan :}

Pada Gambar 1.1 adalah metode perancangan area perkebunan kopi yang dirancang menggunakan teknologi WSN (Wireless Sensor Network), sistem tersebut biasa digunakan di perkotaan sebagai pendukung program Smart City. Pada pengujian ini sistem digunakan untuk memonitoring area perkebunan yang sangat luas serta jangkauan area yang berbeda. Sistem WSN memudahkan pemasangan alat dan sensor pada wilayah perkebunan dan tempat-tempat yang tidak bisa dijangkau oleh kabel dan sumber listrik. Sistem tersebut didukung dengan beberapa hardware dan software sebagai berikut :

\section{a. Kamera}

Kamera pada sistem ini bisa menggunakan kamera standar dan bisa digunakan pada kondisi di luar ruangan. Pada kamera tersebut akan disiapkan program thermal imaging yang akan digunakan untuk mengambil data kondisi tanaman serta area perkebunan.

\section{b. Mobile Phone}

Mobile pada sistem ini digunakan untuk mendata dan mengecek tanaman secara langsung.

\section{c. Mikrokontroler}

Pada sistem ini, mikrokontroler digunakan untuk perantara data yang diinput oleh kamera dengan alat sensor wireless. WSN yang dipasang secara paralel dengan jarak per 30 meter. 


\section{d. Server}

Server pada sistem ini digunakan untuk menyimpan data hasil monitoring dan menyimpan data jenis penyakit yang menyerang kopi serta tanaman kubis. Data yang tersimpan di server telah dirubah ke dalam kode bilangan matrik.

\section{e. Komputer}

Pada bagian ini, komputer digunakan untuk menambah data dan menyimpan hasil monitoring perkebunan. Hasil tersebut bisa digunakan untuk penelitian selanjutnya. Data yang tersimpan dibagi menjadi dua bagian yaitu data training dan data testing, yang berisi jenis penyakit pada tanaman kopi dan kubis yang berupa foto gejala penyakit dan pengendaliannya.

\section{f. Wireles Sensor Network}

Alat Wireless Sensor Network yang digunakan berupa modul wifi dimana modul tersebut akan berfungsi untuk mengirimkan data pada server melalui cloud computing, sehingga sensor bisa dipasang di area dan bersifat flexible.

Tabel 1.1 Jenis Penyakit Pada Tanaman Kopi

\begin{tabular}{|c|c|}
\hline Jenis penyakit & Keterangan \\
\hline Hemelia Vastratix. B & $\begin{array}{l}\text { Penyakit yang menyerang daun kopi yang menyebabkan warna daun kopi } \\
\text { menjadi berbintik-bintik dan kemudian menjadi hitam. } \\
\text { Pencegahan adalah dengan memberikan tanaman dan pemangkasan pada daun } \\
\text { kopi. }\end{array}$ \\
\hline Cendawan Akar & $\begin{array}{l}\text { Menyerang pada daun dan menyebabkan daun menjadi menguning dan lama } \\
\text { kelamaan menjadi rontok. } \\
\text { Pencegahan adalah dengan memberikan penambahan pupuk dan pemangkasan } \\
\text { pada tanaman yang terkena penyakit. }\end{array}$ \\
\hline $\begin{array}{c}\text { Nematode } \\
\text { Pratylenchus coffea }\end{array}$ & $\begin{array}{l}\text { Penyakit ini menyerang daun serta batang pohon kopi yang menyebabkan daun } \\
\text { pada pohon kopi menjadi kerdil dan menguning. } \\
\text { Pencegahan adalah dengan memisahkan tanaman yang terkena penyakit, } \\
\text { memberikan bahan pupuk organik pada tanaman dan membersihkan } \\
\text { pertumbuhan tanaman. }\end{array}$ \\
\hline $\begin{array}{c}\text { Steptiadoderas hampei } \\
\text { Ferr }\end{array}$ & $\begin{array}{l}\text { Penyakit ini menyerang pertumbuhan pada biji kopi, yang disebabkan oleh } \\
\text { hama. Steptiadoderas yang meletakan telurnya pada buah dan lama kelamaan } \\
\text { menjadi keras dan mati. } \\
\text { Pencegahan adalah dengan pemangkasan batang yang terkena penyakit. }\end{array}$ \\
\hline $\begin{array}{c}\text { Pseudococcus citri } \\
\text { Risso }\end{array}$ & $\begin{array}{l}\text { Hama ini menyerang biji dan daun kopi. Hama tersebut biasa menyerang pada } \\
\text { musim kering dan menyebabkan tunas dan buah berguguran. Pada daun } \\
\text { terdapat bintik-bintik hitam sehingga daun dan pohon sekitarnya menjadi } \\
\text { terinfeksi. } \\
\text { Pencegahan adalah dengan memberikan pohong naungan untuk tanaman baru. }\end{array}$ \\
\hline $\begin{array}{c}\text { Xylosandrees morstatii } \\
\text { HAC }\end{array}$ & $\begin{array}{l}\text { Hama tersebut termasuk hama pengerek dan menyerang daun dan buah kopi. } \\
\text { Cabang dan ranting menjadi busuk dan mati. } \\
\text { Pencegahan adalah dengan memotong ranting yang mati pada tanaman yang } \\
\text { terinfeksi. }\end{array}$ \\
\hline
\end{tabular}


Tabel 1.2 Jenis Penyakit Pada Tanaman Kubis

\begin{tabular}{|c|c|}
\hline Jenis penyakit & Keterangan \\
\hline $\begin{array}{l}\text { Akar Pekuk } \\
\text { (Plasmodiophora } \\
\text { brassicae Wor.) }\end{array}$ & $\begin{array}{l}\text { Penyakit pada tanaman yang disebabkan oleh serangan oleh jamur. } \\
\text { Pencegahan adalah dengan meningkatkan kadar } \mathrm{pH} \text { dengan cara pengapuran } \\
\text { dan mengobati tanah dengan pupuk anti fungisida. }\end{array}$ \\
\hline $\begin{array}{l}\text { Bercak Daun } \\
\text { Alternaria (Alternaria } \\
\text { brassicae) Sacc }\end{array}$ & $\begin{array}{l}\text { Penyakit yang disebabkan oleh hama daun dan jamur. } \\
\text { Pencegahan adalah dengan mengobati tanah dengan pupuk anti fungisida dan } \\
\text { memisahkan tanaman yang terkena penyakit. }\end{array}$ \\
\hline $\begin{array}{l}\text { Penyakit Busuk Hitam } \\
\text { [Xanthomonas } \\
\text { campestris pv. } \\
\text { campestris (Pamm.) } \\
\text { Dye] }\end{array}$ & $\begin{array}{l}\text { Penyakit yang menyerang hama dan batang tanaman yang menyebabkan batang } \\
\text { tanaman menjadi coklat dan mengering serta lama-kelamaan daun menjadi } \\
\text { berguguran. } \\
\text { Pencegahan adalah dengan menyemprot tanaman anti jamur dan memisahkan } \\
\text { tanaman yang terkena hama. }\end{array}$ \\
\hline $\begin{array}{l}\text { Penyakit Busuk Basah } \\
\text { [Erwinia caratovora } \\
\text { pv. caratovora (Jones) } \\
\text { Dye] }\end{array}$ & $\begin{array}{l}\text { Hama yang menyerang bercak daun kemudian menyebar pada tanaman } \\
\text { sehingga bercak menjadi besar dan menyebabkan daun kubis menjadi lembab } \\
\text { dan mati. } \\
\text { Pencegahan adalah dengan penanaman tanaman pada jarak yang tidak terlalu } \\
\text { rapat, proses sanitasi dan pengendalian proses pasca panen. }\end{array}$ \\
\hline $\begin{array}{l}\text { Penyakit Kaki Hitam } \\
\text { Phoma lingam (Tode } \\
\quad \text { ex Fr.) Desm.] }\end{array}$ & $\begin{array}{l}\text { Penyakit pada daun menjadi berwarna bintik-bintik kehitaman. Daun muda } \\
\text { yang tumbuh berwarna kemerahan. } \\
\text { Pencegahan adalah dengan memisahkan tanaman yang terkena penyakit dan } \\
\text { memperbaiki sistem sanitasi saat penyemainan tanaman. }\end{array}$ \\
\hline
\end{tabular}

\section{IMPLEMENTASI DAN PENGUJIAN SISTEM}

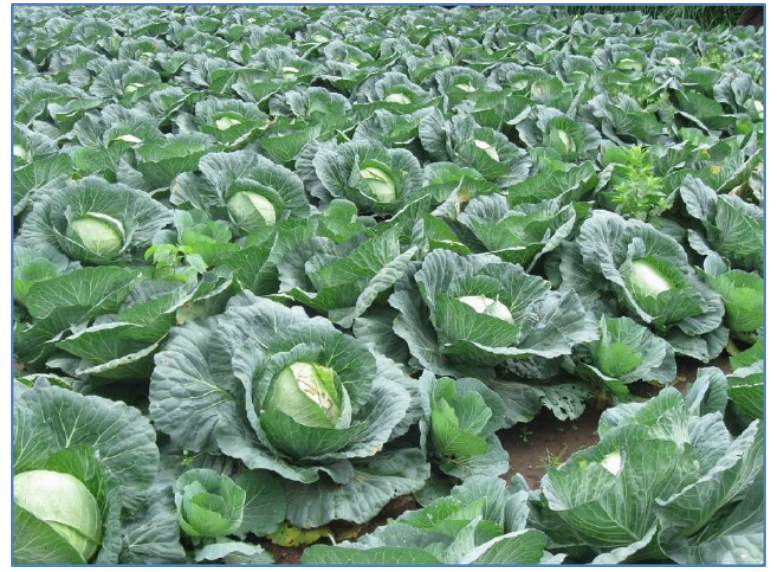

Gambar 1.2 Perkebunan Kubis 


\section{Keterangan :}

Pada Gambar 1.2 adalah pengambilan sampel perkebunan kubis yang akan digunakan sebagai uji coba system. Sistem menggunakan teknik image processing yang akan digunakan untuk melihat keadaan kubis dengan melihat data inputan dari thermal imaging. Sistem kemudian akan menampilkan data bentuk visual warna dimana warna kubis yang sehat dan tidak terserang akan diindikasikan dengan warna biru, sedangkan kubis yang terserang penyakit akan diindikasikan oleh sistem dengan warna kuning.

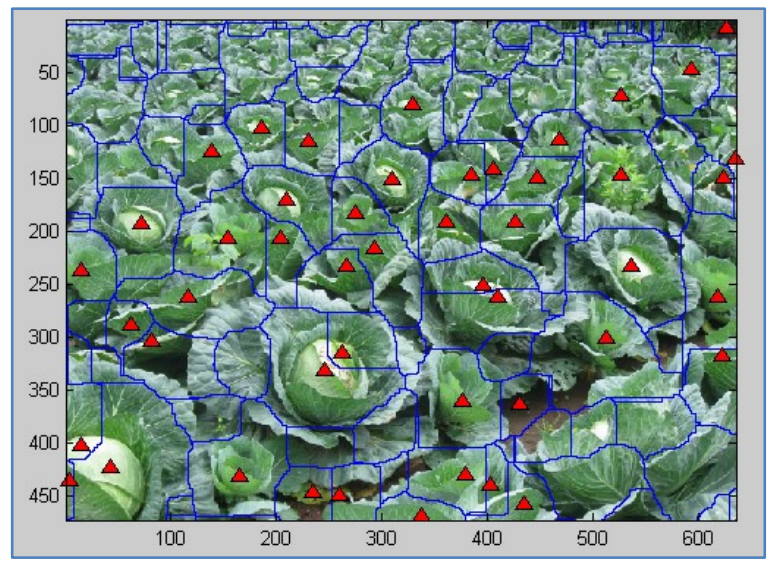

Gambar 1.3 Proses Pemisahan Secara Visual

\section{Keterangan :}

Pada Gambar 1.3 adalah proses pemisahan image kubis dengan teknik segmentasi warna. Pada proses ini data kubis dipisahkan oleh sistem dan diberi tanda marking dengan bentuk segitiga. Komputer secara otomatis akan mengkalkulasikan tiap data dan diameter tiap kubis serta dicatat pada sistem dan tersimpan diserver.

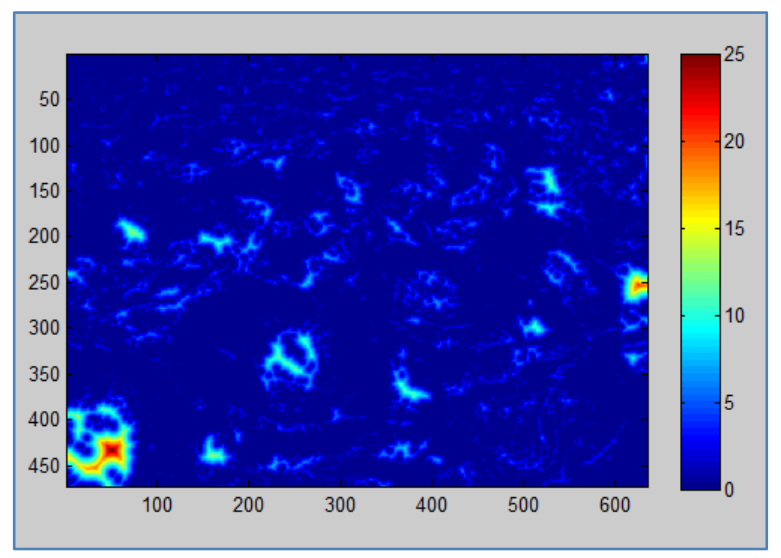

Gambar 1.4 Proses Thermal Imaging

\section{Keterangan :}

Pada Gambar 1.4 adalah hasil analisis dengan thermal imaging yang berfungsi mendeteksi panas dan tanaman yang kering. Sistem ini memberikan tampilan secara visual dalam kode warna dari biru hingga 
merah. Kondisi menandakan tanaman masih cukup air dan dalam kondisi yang baik, sedangkan warna merah menandakan beberapa tanaman dalam keadaan kering. Sistem ini akan membantu mengelola sumber daya penggunaan air sehingga lebih hemat.

\begin{tabular}{|c|c|c|c|c|}
\hline No Tanaman \# & Mean & Intensity & Area & size \\
\hline \# 1 & 138.1 & 269706.0 & 7438.5 & 315.4 \\
\hline \#2 & 103.5 & 2.0 & 2.0 & 1.5 \\
\hline \#3 & 124.2 & 234.0 & 123.8 & 9.0 \\
\hline \# 4 & 123.0 & 6.0 & 7.5 & 2.7 \\
\hline \#5 & 104.5 & 2.0 & 2.0 & 5.0 \\
\hline \#6 & 102.0 & 1.0 & 0.0 & 12.0 \\
\hline \# 7 & 126.9 & 18.0 & 25.1 & 18.8 \\
\hline \# 8 & 102.0 & 1.0 & 0.0 & 16.0 \\
\hline \# 9 & 106.0 & 3.0 & 3.9 & 19.0 \\
\hline
\end{tabular}

\section{Gambar 1.5 Hasil Monitoring Pendataan Setiap Tanaman Kubis}

\section{Keterangan :}

Pada Gambar 1.5 adalah hasil monitoring tanaman kubis pada satu petak area perkebunan. Pada proses ini, sistem akan memberikan penomoran pada tanaman secara visual dan data dari perkembangan tanaman tersebut akan disimpan pada database.

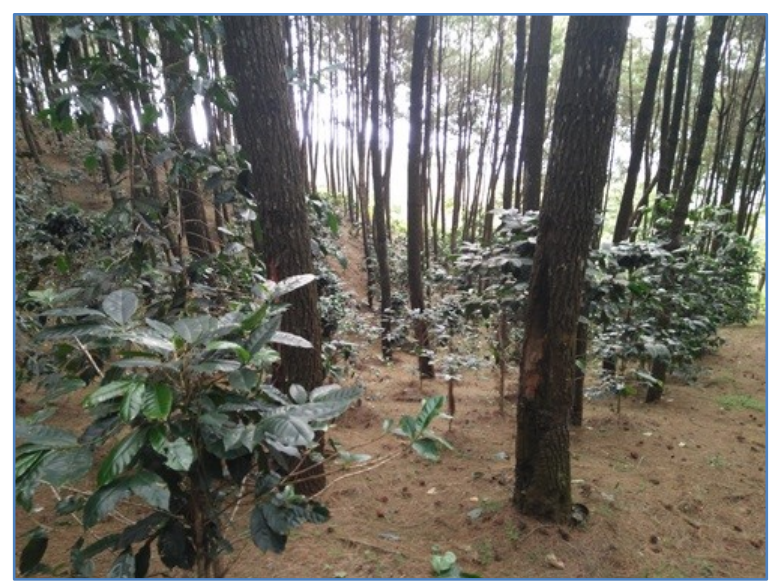

\section{Gambar 1.6 Monitoring Tanamam Kopi Dan Pohon Penaung (Pinus)}

\section{Keterangan :}

Pada Gambar 1.6 adalah kondisi perkebunan kopi daerah Jawa Barat yang biasanya ditanam berbarengan dengan pohon pelindung. Fungsi pohon pelindung tersebut berfungsi agar sinar matahari tidak jatuh langsung pada tanaman, serta menjada kondisi tanah agar tidak longsor. 


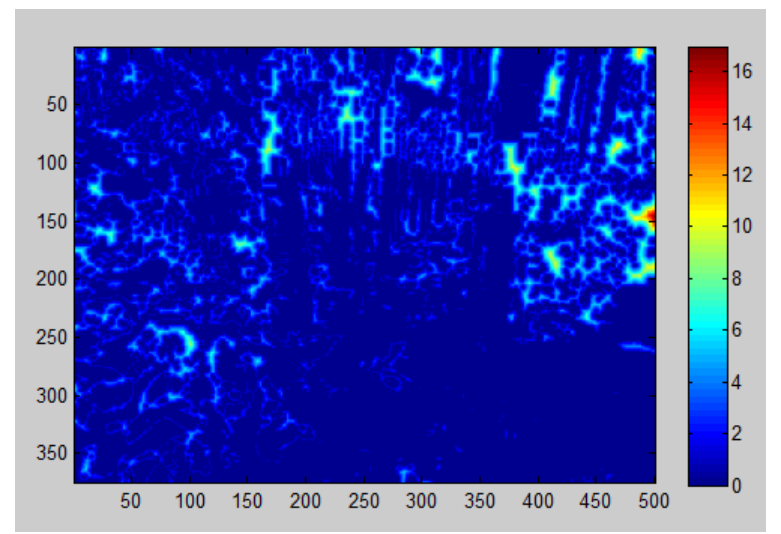

\section{Gambar 1.7 Monitoring Perkebunan Dan Area Pinus}

\section{Keterangan :}

Pada Gambar 1.7 adalah hasil monitoring dengan menggunakan thermal imaging pada pohon kopi dan pinus. Pada gambar tersebut kondisi tanaman masih dalam kondisi aman dan cukup air .

\section{KESIMPULAN}

Pada percobaan penelitian di atas, sistem monitoring daerah area perkebunan kopi dan kubis serta pohon pelindung (pinus) dengan menggunakan teknologi WSN (Wirelesss Sensor Network) dapat diimplementasikan pada area perkebunan kopi. Inputan data diambil dari kemera yang terpasang pada dua tempat yang berbeda yaitu pada area kopi dan tanaman kubis. Pada tanaman kubis teknologi thermal imaging digunakan untuk melihat kondisi pertumbuhan tanaman dan keadaan tanahnya, sedangkan pada tanaman kopi teknologi thermal digunakan untuk melihat kondisi air dan suhu pohon naungan dalam hal ini pohon pinus.

Pada tanaman kubis terletak secara berdekatan sehingga proses penggunaan segmentasi warna pada data tanaman yang diambil dapat dilihat secara otomatis. Data pertumbuhan tanaman dilihat dari diameter tanaman kubis dan kondisi fisik secara langsung dengan parameter perhitungan "area" dan "size". Area = melihat kondisi tanaman yang terjadi perubahan warna atau tidak, jika terjadi maka kemungkinan tanaman terserang hama. Sedangkan size = digunakan untuk melihat ukuran fisik tanaman jika terjadi perbedaan dan tidak ada perkembangan dengan tanaman yang lain maka kemungkinan terserang hama.

Saran untuk penelitian selanjutnya adalah karena alat ini bekerja dengan bantuan kamera dan sensor WSN maka diperlukan proses pemeriksaan yang berkala serta penggunaan sumber listrik, karena alat bekerja selama 24 jam. Pengaturan IP pada alat sensor dibuat secara berurut agar mudah saat pengecekan dan pemeriksaan serta yang terakhir pemeriksaan posisi kamera agar ditempatkan pada area yang memiliki pandangan dan jarak jangkau yang luas. 


\section{DAFTAR PUSTAKA}

[1] Jiménez, M., ; Díaz-Delgado, R., "Towards a Standard Plant Species Spectral Library Protocol for Vegetation Mapping: A Case Study in the Shrubland of Doñana National Park," Geo-Info., vol. 4, no. 4, pp. 2472-2495, 2015.

[2] Nellis, M. D, "Interpretation of thermal infrared imagery for irrigation water resource management," Journal of Geography, vol. 84, no. 1, pp. 11-14, 1985.

[3] Mohan Sridharan ; Prasanna Gowda, "Application of statistical machine learning algorithms in precision agriculture," Asian-Australasian Conference on Precision Agriculture.

[4] Ozdogan, M.; Woodcock, C.E.; Salvucci, G.D.; Demir, H., "Changes in summer irrigated crop area and water use in southeastern Turkey from 1993 to 2002: Implications for current and futurewater resources," Water Resour., vol. 20, pp. 467 - 488, 2006. 